\title{
Prelude to a Theory of Musical Representation
}

\author{
BRANDON POLITE \\ KNOX COLLEGE (bpolite@knox.edu)
}

\section{Introduction}

We questions of whether and how music can represent objects, events, and states of affairs beyond itself has been a going concern within musical aesthetics since at least the nineteenth century. In this paper, I lay the groundwork for an account of musical representation that is largely at odds with most currently on offer within the philosophical literature.

In Section 1, I survey the prevailing philosophical discourse regarding musical representation as it has developed over the past forty years. In doing so, I uncover that it has relied on what I call the Gricean model of artistic representation, according to which representation is a species of meaningful communication similar to linguistic utterances.

In Section 2, I show how those who adopt the Gricean model severely limit music's possibilities as medium for representation. In Section 3, I offer an alternative model for artistic representation that, despite its widespread acceptance outside of the philosophy of art, has been largely denigrated within it: namely, the structural resemblance model.

Finally, in Section 4, I demonstrate how, by overcoming the Gricean model's limitations, the structural resemblance model provides us with a more accurate picture of both (a) how music represents and (b) how we perceive and appreciate musical representations.

What should become clear over the course of the paper is that I am far more optimistic about music's possibilities as a medium for representation than most philosophers of music who explicitly discuss the issue are. 


\section{The Gricean Model}

Roger Scruton set the terms for the current debate surrounding musical representation in his 1976 article "Representation in Music." In that article, Scruton was interested to discover what he would later call a "purely musical route" to representation: "a feature of music that will enable it to present thoughts about something other than itself [to the listener]," without the assistance of a title, text, program, dramatic action, or any other such extra-musical device (SCRUTON, 1997, p. 124; compare to SCRUTON, 1976, p. 274-5). Scruton denies that pieces of music (or parts thereof) intended as representations by their composers-primarily, those we refer to as program music-ever truly represent their intended objects because he is unable to locate a purely musical route through which they can convey thoughts about things beyond themselves.

The idea that works of music would need to "convey 90 thoughts" about things beyond themselves in order to count as representations derives from philosopher of language Paul Grice's influential conception of meaningful communication. In Grice's view, a gesture or utterance means something only if the individual who makes it intends the listener to respond in some way as a result of recognizing in the gesture or utterance her intention for them to do so (GRICE, 1959, p. 383-4; see also GRICE, 1969). Signaling is paradigmatic of this sort of meaning, which Grice (1968, p. 232-3) calls "non-natural meaning" due to its dependence upon human conventions. Extending your left arm straight out while riding a bicycle, for instance, signals to motorists both that you intend to turn left and that you intend for them to alter their behavior if necessary so as to avoid hitting you. Your gesture is meaningful because there is widespread recognition among motorists regarding how you intend for them to respond to it. According to Grice, therefore, whether a gesture or utterance-including an artistic one-is meaningful partially depends upon the ability of other people to recognize the thoughts it was produced or deliberately arranged to convey. 
In light of these considerations, what I will call the Gricean model of artistic representation can be expressed as follows:

(GM) A work of art (or part thereof), $W$, represents a given object, event, or state of affairs, $x$, if and only if

(1) the artist intends to communicate (thoughts about) $x$ to the viewer by means of $W$;

(2) the artist deliberately arranges $W$ so as to facilitate the viewer's ability to grasp (1); and

(3) the viewer is able to grasp that (1) obtains by means of careful inspection of $W$ alone.

Call the first two the "intent" conditions and the third the "success" condition for artistic representation. Scruton builds into the success condition a requirement that in order for a work of art to count as a representation it must be possible, in principle, for the viewer to grasp its intended representational content unprompted-i.e., without any help from the title, program, or any other extra-musical devices the artist may have associated with it. Scruton (1976, p. 281) believes that there are no cases of program music in which the music alone facilitates the listener's ability to grasp the thoughts the artist intends to communicate about the object(s), event(s), or state(s) of affairs (whether real or fictional) she intends it to represent. What actually facilitate it, he believes, are the accompanying extra-musical devices. Since, if true, this would mean that there is no purely musical route to representation, Scruton concludes that music is not a suitable medium for artistic representation.

Despite their differences, Scruton's main interlocutors in the debate surrounding musical representation-namely, Jenefer Robinson, Peter Kivy, and Stephen Davies-agree with at least four aspects of his account. First, they all accept that some form of the Gricean model lies at the heart of artistic representation. While Kivy (2012, p. 201-3) explicitly affirms the Gricean model, its central tenets can also be detected in Robinson's belief that representation is (or, at least, can function as) a form of reference (ROBINSON, 1987, p. 182-3). The Gricean model's intent and success conditions are also 
detectable in Davies' (1994, ch. 2) first and fourth conditions for artistic representation: namely, that a work of art, $W$, counts as a representation only if (1) the artist intends it to represent some object, $x$, and (4) the viewer's ability to recognize $x$ in $W$ depends upon their familiarity with the conventions of the symbol system within which $W$ was produced. ${ }^{1}$

The second point on which Scruton's interlocutors agree with him is that they have all accepted, at one or another point over the course of the debate, his requirement that an artist's representational intentions are only communicated successfully if the viewer can grasp them unprompted. Their third point of agreement follows immediately from this: namely, they all accept that the composer's intention to communicate a particular object with a piece of music (or part thereof) is rarely facilitated by the music alone, but almost always by the extra-musical devices she associates with it. The music alone cannot tell us, for instance, whether a particularly

92 dark and rumbling passage is intended to represent a thunderstorm, a character's emotional state, or a boulder being pushed at night, as Beethoven intends such passages to do in his Sixth Symphony, Coriolan Overture, and Fidelio, respectively. Indeed, the music alone can rarely tell us whether it is intended to represent anything at all, since similar passages occur in pieces of absolute music, which have no representational goals whatsoever. Only the piece's title, program, or other such device can provide us with the particular individual(s) the composer intends the music to represent. As Kivy (2007, p. 211) writes, program music is representational "where the text makes apparent what the music is representing, and the music makes it apparent that the music is representing this by facilitating our experience of hearing the object of representation in the musical fabric." (Compare this claim to ROBINSON, 1987, p. 185-8.)

The preceding claim suggests the fourth point on which Scruton and his main interlocutors agree, one that is

1 Note that Davies' fourth condition is presumed by all of the philosophers I am considering. Thus, when I refer to "the viewer" or "the listener," I have in mind one that is so informed. 
crucial to understanding the debate between them: namely, that Richard Wollheim's "seeing-in" theory of pictorial representation can, perhaps with some qualifications, be extended to provide a general theory of artistic representation. (See SCRUTON, 1976, p. 273; ROBINSON, 1987; KIVY, 1991, p. 217-26; DAVIES, 1994, p. 59-64.) In Wollheim's view, a painting counts as a represent of a given object only if it is possible for a viewer to see that object in the painting; and the viewer's act of "representational seeing" is governed by the artist's deliberate manipulation of the painting's surface features (WOLLHEIM, 1980). As a general theory of artistic representation, therefore, the seeing-in or, rather, perceiving-in view can be expressed as follows:

(PI) A work of art (or part thereof), $W$, counts as a representation of a given object, event, or state of affairs, $x$, if and only if

(1) the artist intends for the viewer to perceive $x$ in $W$;

(2) this intention guides how she arranges $W^{\prime}$ s surface features, namely, so that $x$ can be perceived in them; and

(3) the viewer is able to grasp that (1) obtains by means of perceiving $x$ in $W^{\text {s }}$ s surface features.

This way of presenting it strongly suggests that, rather than offering an alternative model of artistic representation, the perceiving-in view is better understood as a species of the Gricean model. Whether this is so is debatable. ${ }^{2}$ At the very least, similar to the Gricean model, the perceiving-in view conceives of artistic representation as fundamentally dependent upon both the artist's intention to represent and the viewer's ability to grasp them in the work of art. The

${ }^{2}$ Although Wollheim (1988, p. 90) explicitly rejects the Gricean model's conception of representation as communication, arguing that an artist need not intend for her work to communicate anything for it to count as a representation, Anthony Saville (2001) provides compelling reasons why, given Wollheim's more basic commitments, he cannot do so. 
perceiving-in view can thus be viewed as refining the Gricean model by specifying precisely how the artist facilitates the viewer's ability to grasp her representational intentions: namely, by arranging her work's surface features in such a way that the object she intends it to represent can be perceived in them. In this way, the perceiving-in view fits with-if not wholly within - the Gricean model.

The fact that Scruton, Robinson, Kivy, and Davies all maintain versions of the perceiving-in view further reinforces my claim that the Gricean model or, at least, its basic assumptions have underpinned the prevailing discourse regarding musical representation within the philosophical literature for the past forty years. This is not to suggest, however, that Scruton's three main interlocutors share his extreme pessimism toward music's representational capacities. All three allow that at least some pieces of program music (or parts thereof) can facilitate our experience of extra-musical

94 objects using purely musical means and thereby count as representations. In the next section, I present the general picture of musical representation to which their shared adherence to the Gricean model commits them and reveal its limitations. From there, I present the structural resemblance model and show how it overcomes the Gricean one's limitations and thereby offers us a more accurate picture of musical representation.

\section{The Gricean Model's Limitations}

As I just mentioned, Robinson, Kivy, and Davies all agree that some pieces of music can communicate their representational content to us without the aid of such extramusical devices as a title or program. They further agree that this occurs only in those moments in which a piece of music draws attention to itself, which most often occurs when it noticeably departs from the musical conventions of the tradition within which it was produced. (See ROBINSON, 1981; KIVY, 1984, p. 213-5; and DAVIES, 1994, p. 93-7.) Whenever we encounter a moment we have difficulties making sense of in purely musical terms, we recognize that it could signal, in the 
Gricean sense, that the composer intends it to communicate something to us. These unexpected disruptions of our musical expectations direct our attention away from the music itself and toward whatever it might represent. Most often, these "disruptive signals," as I shall call them, direct us toward any extra-musical devices the composer might have associated with the music. Where such devices exist, they confirm our suspicion that the piece has representational aims as well as provide us with the object(s) the composer intends her piece to represent. This alleviates any confusion we may have initially experienced as to why the composer would have included such peculiar passages within an otherwise conventional piece of music. Since it is the music itself that draws our attention toward something beyond itself, even if we usually cannot identify that something until after we have appealed to the extra-musical devices, disruptive signaling counts as a purely musical route to representation.

Davies believes that only two sorts of disruptive signals are conducive to musical representation. I call them "felicitous imitation" an "exotic instrumentation." (See DAVIES, 1994, p. 93-7.) The felicitous imitation of a cuckoo call in Beethoven's Sixth Symphony, for example, is peculiar enough within its musical surroundings that any listener familiar with real-life cuckoos will hear the music as representing one. Similarly, we do expect to hear the firing of actual rifles when we go to a performance of classical music. Beethoven exploits this fact in Wellington's Victory to signal to the reader that the battle is underway. Tchaikovsky uses cannon fire toward the same end in his 1812 Overture. Both felicitous imitation and exotic instrumentation rely on the fact that we regularly identify objects by the sounds they emit. In both cases, the piece of music sounds so much like a particular real-world sound that it takes us out of the musical moment at the same moment it enables us identify its representational content. Robinson's (1987, p. 185-6) view is stricter than Davies' view in that the only legitimate instances of musical representation she mentions are felicitous imitations. ${ }^{3}$ Despite this potential

${ }^{3}$ It must be noted that Robinson's view has softened significantly since 1987. Together with Gregory Karl, she has recently argued- 
difference, Robinson and Davies both restrict the resemblances that disruptive signals can exploit in order to achieve representational ends to purely auditory ones-i.e., resemblances of sounds by other sounds.

In contrast, Kivy (1984, p. 206-13) believes that disruptive signals can exploit resemblances of almost any sort, and not merely of the sound-to-sound variety, in order to represent extra-musical objects. They do so, in his view, only when we can no make sense of them whatsoever in purely musical terms. In support of this belief, Kivy adduces Haydn's representation of God shining light upon the chaos in the first movement of his Creation oratorio:

At the opening of the Creation, after the representation of chaos (Die Vorstellung des Chaos), Haydn muddles about in the key of $\mathrm{C}$ minor, in subdued tones and low registers, with the chorus and bass soloist accompanied only by muted strings. The sound is dark throughout, and reaches its nadir on the words: "And God said: Let there be light, and there was...," sung by the chorus a capella, in unison. But when the word "light" occurs again, in "and there was light," the full orchestra, woodwind, brass, strings unmuted, comes on like Gangbusters, on the "brightest" imaginable C-major chord. (KIVY, 1984, p. 68)

In this case, the musical resolution of darkness into brightness does not sound like its intended object because visual phenomena do not sound like anything. This passage nevertheless shares a structure with any brightness-replacingdarkness event, even if visual and musical brightness and darkness are of distinct kinds. (The latter may be metaphorical while the former are literal.) By Kivy's lights, then, the passage succeeds as a representation, first, because it exploits this sound-to-vision resemblance effectively and, second, because

quite rightly, in my view - that pieces of program music often make perfect musical sense while still counting as representations; see Karl and Robinson (2015, p. 21). It is unclear, however, whether this means that she no longer accepts the Gricean model of artistic representation. 
the resolution to $\mathrm{C}$-major is so unexpected that it signals Haydn's representational intentions to us.

While I agree with Kivy on the first point, his acceptance of the second indicates what I take to be his account's most significant limitation. As I discussed above, Kivy's commitment to the Gricean model forces him to identify a purely musical route to representation. He believes that wholly unmusical disruptive signals provide the only such route. It follows from this, however, that any passage that we can fully account for in purely musical terms cannot possess representational content. This is so even if the composer had deliberately arranged the passage so that we would hear (aspects of) a given object in it. (In support of this claim, see Kivy, 1984, p. 209.) But it seems reasonable to assume that composers of program music wish for their pieces to succeed not only as representation but also as music. Among the greatest achievements of this sort of music are those pieces that appear to succeed in both ways. To my mind, the passage from Haydn's Creation that Kivy adduces is just such an example. Just because the resolution to C-major may be unexpected or peculiar enough to draw attention to itself does not mean that it is also unmusical. The same is true of the cuckoo call in Beethoven's Sixth Symphony, the gunshots in his Wellington's Victory, and the cannon fire in Tchaikovsky's 1812 Overture. There is a difference between a piece of music departing from musical conventions and it making no musical sense. Kivy appears to conflate the two, whereas Robinson and Davies do not. As Davies (1994, p. 101-2) notes against Kivy, peculiar and unexpected passages regularly occur in pieces of absolute music. (Davies offers this point, however, as further support for his belief that music's representational capabilities are severely limited.) Even if such passages always constitute deficiencies, which is a claim I would contest, nearly all of them will nonetheless make at least some musical sense within their respective pieces.

Despite their differences, the foregoing discussion reveals that Robinson, Kivy, and Davies all accept that composers who successfully produce musical representations do so primarily, and perhaps even exclusively, by means of exploiting natural resemblances between musical sounds and 
extra-musical objects-especially other sounds. This is a significant contribution to the philosophical discourse on musical representation. Where they go wrong, however, is in attempting to force the exploitation of natural resemblances into the box provided for it by the Gricean model. They do so, in particular by treating it as a mere means to the ultimate end of successful (i.e., unprompted) communication. In contrast, I believe that we should make the exploitation of natural resemblances primary within our conception of artistic representation. Doing so, I believe, will help us to better understand the role that communication actually plays in the production and appreciation of representational works of art. I spend the remainder of the paper defending these claims.

\section{The Structural Resemblance Model}

Resemblance theories of representation have proliferated outside of the philosophy of art since the 1980s. Philosophers in several fields have particularly advocated for 98 the centrality of structural resemblance, particularly isomorphism, to representation. Robert Cummins (1989 and 1996), Douglas Hofstadter (1999 and 2007), and others have appealed to isomorphisms to explain such diverse phenomena as human perception, memory, and intelligence. Bas Van Frassen (1980 and 2008), Jonathan Waskan (2006), and others have used isomorphisms to explain how scientific theories capture reality. Malcolm Budd (1993) has argued that paintings represent by means of exploiting partial isomorphisms between their surface features and their intended objects. And Christopher Peacocke (2009) believes that we perceive music's expressive properties by subconsciously exploiting isomorphisms between musical structures and those of extramusical phenomena. I am thus by no means alone in advancing a structural resemblance model of representation.

In my view, pieces of program music represent their intended objects by exploiting antecedent structural resemblances to them. These resemblances could be isomorphisms; however, I see nothing to prevent weaker structural relations, including partial isomorphisms and homomorphisms of various sorts, from being conducive to artistic representation. Whatever the specific kind(s) of 
structural resemblances a piece of program music exploits, we grasp its representational content simply by noticing them. Take Ralph Vaughan Williams' The Lark Ascending. In hearing the violin melody as ascending, we recognize the lark as similarly ascending. Every instance of musical representation, I claim, is of precisely this sort. Because of this, language is not a good model for representation. Exploiting antecedent resemblances to secure reference rarely happens in linguistic communication. This is because nearly all of linguistic communication is purely conventional, since the relationship between words and their referents is almost entirely arbitrary.4 But structures, such as that of ascent, possess their potential for exploitation independently of anyone's intention to exploit them. That is, the similarity between a lark's ascent and any melodic ascent exists regardless of whether Vaughan Williams intended his piece to represent a lark's journey. A piece of music's representational content, therefore, cannot be purely conventional in the way that most linguistic content is. Music simply does not "represent" in the same way that language "means."

That we perceive and understand a musical line as ascending is certainly connected with the convention of labeling some notes as high and others as low. Any other binary relation could have been arbitrarily selected to describe relative pitch-difference but as a matter of historical fact was not. That we label pitches in this way is what allows us to recognize the structural similarity that Vaughan Williams exploits between the music's and the lark's ascent. But the resemblance exists prior to our recognition and labeling of it. It is this sense in which it is "antecedent." As a result, while linguistic convention facilitates our recognition of the work's representational content, it neither creates nor grounds it. How we perceive music is, to a large extent, pre-structured: based on learned mental schemas derived from our prior experiences with a wide variety of works within the Western repertory.

\footnotetext{
${ }^{4}$ The one exception to this is onomatopoeia; yet, even here the imitated sounds are verbally rendered using conventions of the language into which they are rendered.
} 
While historically rooted in linguistic conventions, perceiving and understanding a musical line as ascending-or drooping, lethargic, sprightly, bright, tender, and so on-has become entrenched within our tacit listening dispositions. 5 Vaughan Williams and other composers exploit this fact when arranging not only pieces of program music but pieces of absolute music as well.

Although artistic representations are grounded upon non-arbitrary (i.e., natural) resemblances, they nonetheless retain some element of the arbitrary. The arbitrary element in a piece of program music is simply the composer's stipulation, normally expressed in the extra-musical devices, that she intends it as a representation. The mere presence of this stipulation sets the terms for representational success. In short, a piece of program music is to be evaluated for success or failure in terms of how well the music enables us to grasp whatever object(s), event(s), or state(s) of affairs the 100 accompanying extra-musical devices refer to, describe, or imply. This reflects our actually listening practices, which are such that we treat the extra-musical devices as establishing a correspondence scheme between the music and its intended object, which our imaginative engagement with the piece fleshes out and fills in as it unfolds before our ears. Stated simply, we use the extra-musical devices to prime our musical expectations. From the title of the second movement of Beethoven's Sixth Symphony, "Scene at the Brook," we expect to hear flowing melodies and glistening harmonies. But the title does not fully determine the aspects of the scene targeted by and rendered in the music. Instead, it gives us an imprecise description of some of the piece's extra-musical targets (particularly, brook-like sounds), which serves to delimit the field of possible resemblances that we should attend to in order to grasp and appreciate its representational content.

${ }^{5}$ Kendall Walton (1994) points to this fact when he claims that all music is representational. However, since his view is such an outlier and not properly engaged with the debate I am interested in, I have left it out of the current discussion. 
Since there are many ways a piece of program music could resemble its intended object, how successfully the music communicates it to us will largely depend upon which of its aspects the composer chose to render and the musical dimensions along which she chose to do so. All representations are abstractions from and distortions of their objects. Artistic representations consequently operate by means of a sort of synecdoche or metonymy wherein certain aspects of the object, or of things associated with it, are targeted by the artist and subsequently rendered in the artwork. In Till Eulenspiegel's Merry Pranks, for example, Richard Strauss musically renders a giggle as a leitmotif that represents the satisfied trickster who giggles in anticipation of his next misadventure. Similarly, Beethoven expresses a complex series of moods in the Coriolan Overture to represent the Roman-turned-Volscian general that felt them.

In light of these considerations, there are two main factors that jointly impact how readily we can grasp a work of art's representational content: (a) salience, or how strongly the aspects targeted by and rendered in the work of art are connected with its intended object(s) in our minds; and (b) accuracy, or how closely the music resembles those aspects. In practice, salience is often the more important of the two. For instance, Beethoven's nightingale and quail songs in the Sixth Symphony are impressionistic and highly inaccurate compared to the birdsongs Olivier Messiaen meticulously rendered for piano in his several catalogues of bird works. Yet, Beethoven's less accurate birdsongs are readily recognizable as such from the music alone (even if we need to appeal to the program to identify what bird species they represent), whereas as Messiaen's far more accurate ones rarely are. This is because, unlike Messiaen, Beethoven preserved the birdsongs' timbres, which are among their most salient features, by scoring them for the appropriate instruments: the flute for the nightingale and oboe for the quail.

\section{Overcoming the Gricean Model's Limitations}


Despite his adherence to the Gricean model, Kivy provides us with a compelling reason to accept the view I have just presented. He writes, "Musical structure is there waiting to be used, by composers like Berlioz and Richard Strauss, to illustrate and represent" (Kivy, 2002, p. 1999). On the same page, he also notes that antecedent structural resemblances between pieces of music and things in the world are "why it is so easy to put fictional stories to absolute music. All you need to do is fit your fictions to that music." Music can resemble countless things in innumerable ways. ${ }^{6}$ Music can be dark, sad, trembling, ascending, surprising, dialogical, and so forth. Composers exploit this fact whenever they deliberately arrange their pieces to achieve representational ends. To ensure that we pay attention only to those resemblances that advance their particular representational ends and ignore the countless others that do not, composers give their pieces descriptive titles and provide us with programs and other extra-musical devices. While this fact poses no problems on my view, it is 102 responsible for much of the skepticism about music's status as a medium for artistic representation that I discussed above.

Recall that the main charge against program music is that in most, if not all, cases it is the program rather than the music itself that secures the representation of a work's intended object. Davies (1993, p. 20) reports that "Schumann was tricked, apparently, into thinking he was listening to Mendelssohn's Italian Symphony when he was hearing the Scottish Symphony by that composer. He had no difficulty 'seeing' in the work Italian landscapes and vistas with incredible detail." The general worry is that we could come to hear almost anything in almost any work of program music with only the slightest prompting. This contrasts sharply with most instances of non-abstract painting. Had Picasso selected The Barking Dog as the title for his The Old Guitarist, for

\footnotetext{
${ }^{6}$ It is this fact regarding musical structure in particular that inspires Charles Nussbaum's (2007, p. 126) claim that "all Western tonal art music since 1650, including pure music, is program music." I have relegated his view to the footnotes for the same reasons I relegated Walton's to them.
} 
instance, we would never come to see the man in the painting as a dog no matter how much effort we devoted to the task. Yet, it seems that no matter what descriptive title Mendelssohn had given the Scottish Symphony-be it the Italian Symphony, Forest Fire, or Dancing Bunnies - we could almost certainly find much in the music that resembles the object(s) to which its title refers. The problem, in short, is that we are almost always "fitting fictions" to the music rather than the music itself generating those fictions for us.

One possible way to avoid this argument would be to treat pieces of program music similar to musical drama and opera: namely, as hybrid works of art. This would circumvent the need for a purely musical route to representation, since pieces of program music would not belong to the class of pure music. Davies (1993, p. 21-2) suggests that we should do just that. In doing so, Davies argues that it is not the music alone but rather the text-music or drama-music hybrid that is responsible for representing the intended object. ${ }^{7}$ But texts do not represent; they refer, describe, and imply. Although they may facilitate our grasp of the music's representational content, the extra-musical devices do not represent them. As a result, even if Davies were correct that program music is an art form distinct from music properly so-called, and I think we have good reason to believe that he is, it would nevertheless be the music that does the representing-specifically, by resembling structures possessed by the objects that the accompanying extra-musical devices refer to, describe, or imply. In this sense, the exploitation of antecedent structural resemblances constitutes a purely musical route to representation.

Prompted by the extra-musical devices, we come to a piece of program music with an indefinite list of possible targets in or associated with its intended object, which are likely weighted by degree of likelihood. (The bulk of this "list" will be generated with little conscious effort.) In the “Thunderstorm" movement of Beethoven's Sixth Symphony, for

${ }^{7}$ Scruton (1997, p. 126) shares this assessment. 
instance, it is far more likely that we will hear the musical rendering of thunder-dark timbres, low registers, rumbling rhythms, fluctuating dynamics with multiple crescendos, and the like-than of woodland creatures scurrying for cover. Prior expectations of this sort inform our experience of the music as it unfolds, as we seek out (in a largely unreflective way) the resemblances that ground the piece's representational content. Sometimes the music bears out our prior expectations, other times it does not, and still other times we discover objects we did not expect to hear in it. Our expectations change while the piece unfolds, as new expectations engendered by the music reach back and augment those initially engendered by the extra-musical devices.

I consider the preceding to be an accurate description of how we actually perceive and appreciate pieces of program music. This contrasts with the general picture that Robinson, Kivy, and Davies offer us, which I provided in the previous

104 section. In brief, they believe that we listen to a piece of program music as pure music (or purely in terms of its music) until we encounter a passage that in some way draws attention to itself. Whenever this occurs, we either immediately grasp the passage's representational content or else we appeal to the corresponding extra-musical devices to discover what its content is. With our curiosity now satisfied, we go back to listening to the piece as if it were absolute music - that is, until we encounter another such moment, which causes the process to repeat itself. This way of characterizing our listening practices-namely, as comprised of long stretches of largely unreflective engagement with the musical line that are occasionally interrupted by moments of extra-musical reflection-fails to capture just how dynamic the process of understanding and appreciating musical representations truly is. Understanding and appreciating musical representations, in my view, involves a continual dialectical engagement between reflective and unreflective judgments that mutually qualify each other throughout our experience of the piece.

In general, to recuperate a piece of music's representational content, i.e., to perceive and appreciate the connections between the music and whatever it is intended to represent, we must sift through their numerous resemblances 
and attend to those that are representationally relevant while the piece unfolds before our ears. But not just any resemblances will do if the representation is to be musical as opposed to merely sonic. Resemblances along the structural dimensions of melody, harmony, rhythm, timbre, dynamics, and expression will be of primary importance to a piece of music's status as a representation. The exploitation of structural similarities between pieces of music and things beyond them allows music to break free from representing only auditory phenomena and to represent non-auditory objects, events, and states of affairs. Although he may have been wrong about the mechanism through which musical representation ultimately secured (i.e., disruptive signaling), Kivy nevertheless offers us a key insight into the nature of musical representation. Or, rather, he reintroduced us to an insight that arch-formalist Eduard Hanslick originally offered in the mid-nineteenth century:

The fall of snowflakes, the flutter of birds, and the rising of the sun-these I can paint musically only by analogy, by producing audible impressions dynamically related to them. In pitch, intensity, tempo, and the rhythm of tones, the ear offers itself a configuration whose impression has that analogy with specific visual perception which different sense modes can attain among themselves. (Hanslick, 1986, p. 20)

There is thus a very real sense in which I have elaborated and defended Hanslick's conception of musical representation in this paper.

\section{Conclusion}

By way of conclusion, I will simply adduce what I take to be the central insights that the structural resemblance model offers us into the nature of musical representation. First, it shows that a composer's intention to represent a given object can be musically realized through the exploitation of antecedent resemblances along the structural dimensions of melody, harmony, rhythm, timbre, dynamics, and expression. Second, it shows that experiencing a piece of program music involves a dialectical interplay wherein expectations prompted by both the program and the music feed back into and mutually 
refine each other throughout the piece's duration. Third, it shows that a musical representation will be successful if its composer targets salient aspects of either the extra-musical object or things closely associated with it and renders them accurately enough so that the resemblances between the music and its targets are recognizable. Finally, it establishes that linguistic conventions often facilitate the recognition of those resemblances, but neither create nor ground them. By clarifying these issues, my theory offers a better alternative to the prevailing (Gricean) conceptions of musical representation that are currently on offer within the philosophical literature. ${ }^{8}$

\section{References}

BUDD, Malcolm. How Pictures Look. In: KNOWLES, Dudley; SKORUPSKI, John (Eds.). Virtue and Taste. Oxford: Clarendon Press, 1993. 154-75.

CUMMINS, Robert. Meaning and Mental Representation. Cambridge, MA: MIT Press, 1989.

. Representations, Targets, and Attitudes. Cambridge, MA: MIT

Press, 1996.

DAVIES, Stephen. Musical Meaning and Expression. Ithaca, NY: Cornell University Press, 1994.

. Representation in Music. Journal of Aesthetic Education, v. 27, n. 1, p. 16-22, Spring, 1993.

GRICE, H. P. Meaning. The Philosophical Review, v. 66, n. 3, p. 377-88, Jul., 1959.

. Utterer's Meaning and Intentions. The Philosophical Review, v.

68, n. 2, p. 147-77, Apr., 1969.

${ }^{8}$ Earlier versions of this paper were presented at the American Philosophical Association Pacific Division meeting (San Francisco, 2013) and the American Society for Aesthetics Eastern Division meeting (Philadelphia, 2014). I would like to thank both audiences for instructive feedback and especially my two commentators, Erum Naqvi and David Davies. I would also like to thank Steven J. Wagner, Barbara Sattler, Robert Cummins, James D. Wallace, Gary Ebbs, Krista K. Thomason, and Tyler Fagan for substantive comments on drafts at various stages in the paper's development. 
Utterer's Meaning, Sentence Meaning, and Word-Meaning. Foundations of Language, Dordrecht, v. 4, n. 3, p. 225-42, Aug., 1968.

HANSLICK, Eduard. On the Musically Beautiful: A Contribution Towards the Revision of the Aesthetics of Music. Translated by G. Payzant. Indianapolis, IN: Hackett, 1986.

HOFSTADTER, Douglas R. Gödel, Escher, Bach: An Eternal Golden Braid. New York: Basic Books, 1999.

. I Am a Strange Loop. New York: Basic Books, 2007.

KARL, Gregory; ROBINSON, Jenefer. "Yet Again, 'Between Program and Absolute Music."' British Journal of Aesthetics, Oxford, v. 55, n. 1, p. 1937, Jan., 2015.

KIVY, Peter. In Defense of Musical Representation: Music, Representation, and the Hybrid Arts. In: . Music, Language, and Cognition: And Other Essays in the Aesthetics of Music. Oxford: Oxford University Press, 2007, p. 199-213.

. Introduction to a Philosophy of Music. Oxford: Clarendon Press, 2002.

. Music in Memory and Music in the Moment. In: New Essays in Musical Understanding. Oxford: Clarendon Press, 2001, p. 183-217.

Pictures, Representations, and Hearing-in. In: Sound and Semblance: Reflections on Musical Representation. Princeton, NJ: Princeton University Press, 1991.

. Sound and Semblance: Reflections on Musical Representation. Princeton, NJ: Princeton University Press, 1984.

. Sounding Off. Oxford: Oxford University Press, 2012.

NUSSBAUM, Charles. The Musical Representation: Meaning, Ontology, and Emotion. Cambridge, MA: MIT Press, 2007.

PEACOCKE, Christopher. The Perception of Music: Sources of Significance. British Journal of Aesthetics, Oxford, v. 49, n. 3, p. 257-75, Jul., 2009.

ROBINSON, Jenefer. Music as a Representational Art. In: ALPERSON, Philip (Ed). What is Music? An Introduction to the Philosophy of Music. Philadelphia: Pennsylvania State University Press, 1987, p. 165-92.

. Representation in Music and Painting. Philosophy. Cambridge, v. 56, n. 217, p. 408-13, Jul., 1981.

SAVILLE, Anthony. Communication and the Art of Painting. In: VAN GERWIN, Rob (Ed.) Richard Wollheim on the Art of Painting: Art as 
Representation and Expression. Cambridge: Cambridge University Press, 2001, p. 75-84.

SCRUTON, Roger. Representation in Music. Philosophy, Cambridge, v. 51, n. 197, p. 273-87, Jul., 1976.

. The Aesthetics of Music. Oxford: Oxford University Press, 1997.

VAN FRAASSEN, Bas C. The Scientific Image. Oxford: Clarendon Press, 1980.

. The Scientific Representation: Paradoxes of Perspective. Oxford: Clarendon Press, 2008.

WALTON, Kendall. Listening with Imagination: Is Music Representational? Journal of Aesthetics and Art Criticism, Hoboken, v. 52, n. 1, 47-64, Winter, 1994.

WASKAN, Jonathan. Models and Cognition: Prediction and Explanation in Everyday Life and in Science. Cambridge, MA: MIT Press, 2006.

WOLlHEIM, Richard. Painting As an Art. Princeton, NJ: Princeton University Press, 1988. 137-51. 